\title{
CONTRIBUICÕES DO PROGRAMA DE MONITORIA PARA A FORMAÇÃO ACADÊMICA E DOCENTE DO MONITOR LICENCIANDO EM CIÊNCIAS BIOLÓGICAS
}

\author{
Ednalva Alves Vital dos Santos ${ }^{1}$ \\ ${ }^{1}$ Mestre em Biodiversidade pela Universidade Federal da Paraíba- UFPB, Campus II Areia \\ E-mail para correspondência: ednalva.avs@gmail.com
}

\section{Resumo}

\begin{abstract}
O presente trabalho objetivou analisar experiências vividas no programa de monitoria nas disciplinas de Morfologia e Anatomia Vegetal e Sistemática de Fanerógamas, no curso de Ciências Biológicas. Durante os períodos 2013.2 e 2014.1 foram realizadas as atividades de acompanhamento e orientação dos alunos regulares das disciplinas, bem como de esclarecimento de dúvidas e revisões de conteúdos teóricos ministrados em aula. O exercicio da monitoria contribuiu na construção da identidade docente da monitora, na apropriação de conhecimentos, auxiliando o processo de ensino-aprendiagem das disciplinas, diminuindo as lacunas de aprendiagem dos alunos nos conteudos de Morfologia, Anatomia e Sistemática, construindo saberes em botânica e, melhorando as relações professor-aluno-conheciento. A monitoria foi portanto um diferencial para a promoção crescimento e desenvolvimento dentro da academia, bem como estimuladora para atuação docente, uma vez que atividades realizadas e as experiências vividas juntos aos alunos e o professor orientador trouxeram subsídios que contribuíram no aperfeiçoamento da formação acadêmica e formação inicial docente, tanto quanto para a formação dos alunos e desenvolvimento da Instituição.
\end{abstract}

Palavras-chave: Ensino de Botânica, Formação de professores, EnsinoAprendizagem

\begin{abstract}
The present work aimed to analyze experiences lived in the monitoring program in the disciplines of Plant Morphology and Anatomy and Systematics of Phanerogams, in the Biological Sciences course. During the periods 2013.2 and 2014.1, the activities of monitoring and orientation of regular students of the disciplines were carried out, as well as clarifying doubts and revisions of theoretical content taught in class. The monitoring exercise contributed to the construction of the teacher's teaching identity, in the appropriation of knowledge, helping the teaching-learning process of the subjects, reducing the students' learning gaps in the contents of Morphology, Anatomy and Systematics, building knowledge in botany and, improving teacher-student-knowledge relations. Therefore, monitoring was a differential for promoting growth and development within the academy, as well as stimulating teaching activities, since the activities carried out and the experiences lived together with the students and the advisor professor brought subsidies that contributed to the improvement of academic education and training
\end{abstract}


initial teaching, as much as for the training of students and development of the Institution.

Keywords: Botany Teaching, Teacher Training, Teaching-Learning

\section{Introdução}

O processo de ensino aprendizagem compreende um cenário no qual professores e alunos, são figuras emblemáticas, cujo papel principal está no ato de ensinar e aprender. Esse processo, não necessariamente segue-se a regra, que o professor ensina e o aluno aprende, além desse paradigma, existe o compartilhamento de saberes no qual professores e alunos ensinam e aprendem juntos. Embora pareça simples, por traz do exercício pedagógico há fortes complexidades, em diversos aspectos que dificulta o ótimo desse processo, havendo naturalmente a necessidade de adir outros personagens que auxilie na condução desse processo, e torne-o mais palatável aos envolvidos. Os programas de monitoria neste sentido, tem contribuído relevantemente na melhoria das relações professor-aluno-conhecimento.

A Monitoria é um programa Institucional que oferece aos alunos regularmente matriculado nos cursos de Graduação a oportunidade de desenvolver atividades teóricas e práticas junto aos alunos monitorados sob a orientação e supervisão de um professor. Nesse aspecto, a Monitoria, principalmente em cursos de Licenciatura, tem por objetivo despertar nos alunos o interesse pela docência como também promover a cooperação entre docentes e discentes e assim também aprimorar a formação acadêmica e de ensino. De acordo com Lei № 5.540, de 28 de novembro de1968, Art. Art. 41. As universidades deverão criar as funções de monitor para alunos do curso de graduação que se submeterem a provas específicas, nas quais demonstrem capacidade de desempenho em atividades técnico-didáticas de determinada disciplina (Brasil, 1968).

Segundo Frison e Moraes (2010), e Vicenzi et al. (2016), a monitoria compreende uma estratégia de apoio ao ensino; onde estudantes que se destacaram ou que se apresentam mais adiantados, podem colaborar na construção do conhecimento de seus colegas através da ação intermediada e baseada em seus próprios conhecimentos e vivências pedagógicas.

Para Amato e Reis (2016), a monitoria permite ao monitor trabalhar em grupo e confrontar ideias, o que contribui para uma aprendizagem colaborativa 
entres as partes envolvidas. Além disso, a monitoria traz ao estudante a possibilidade de se aprofundar em conhecimentos de determinada área na qual ele pode se identificar e seguir convicto de suas escolhas acadêmicas (ASSIS et al., 2006). O programa também proporciona uma assistência aos alunos que, em primeira instância, pode inferir na redução do número de evasão da sala de aula e possíveis reprovações (SOUZA; GOMES, 2015; FRISON E MORAIS, 2010).

Mediante a ementa de qualquer disciplina é regra concluir os conteúdos programáticos no tempo estabelecido, e muitas vezes não há tempo para discussões mais abrangentes sobre os conteúdos, e isto pode comprometer a aprendizagem. Neste aspecto é comum haver entre alunos e professores o distanciamento de articulação e dialogo com relação aos conteúdos abordados. A falta de aproximação das pessoas e ideias gera muitas vezes a falta de interesse, de entendimento e, consequentemente, baixo índice de aprendizagem.

Santos e Lins, (2007) ao tratarem sobre a necessidade de apoio ao ensino e a aprendizagem dos alunos afirmam que:

[...] é indispensável apoios pedagógicos competentes para ajudar aos professores a compreenderem as potencialidades dos estudantes, possibilitando a realização de um trabalho que leve os estudantes a superar os momentos críticos de inserção no ensino superior (SANTOS E LINS, 2007, p. 22).

Nesse contexto, a monitoria se apresenta como uma alternativa para que o aluno busque auxílio para aprendizagem sob uma dinâmica diferente de uma situação convencional de sala de aula, na qual o monitor atua como um mediador na relação professor - aluno, e vive experiências que mais tarde serão relevantes na decisão de se tornar ou não um profissional docente (BARBOSA; AZEVEDO; OLIVEIRA, 2014).

Considerando a pertinência da monitoria na formação acadêmica e docente, este trabalho teve como objetivo descrever as experiências vividas na monitoria de Morfologia e Anatomia vegetal e Sistemática e fanerógamas, bem como as contribuições do programa para a formação docente e acadêmica do monitor licenciando. 


\section{Metodologia}

O trabalho foi desenvolvido a partir de um relato de experiência, da aluna (autora) do curso de graduação em Ciencias Biológicas da Universidade Federal de Campina Grande- Centro de Educação e Saúde - CES/UFCG, campus Cuité-PB, Brasil.

O relato conta com descrições, considerações e ponderações embasadas nas experiências vividas como monitora durante o exercício da monitoria nas disciplinas de Morfologia Anatomia e Vegetal e Sistemática de Fanerógamas, respectivamente do(s) semestre(s) 2013.2 e 2014.1. A admissão no programa de monitora se deu a partir de um processo seletivo (EDITAL PRE № 035/2013 e EDITAL PRE № 014/2014), com provas de conhecimentos específicos e práticos, para alunos que já haviam cursado e aprovado nas disciplinas ora citadas.

Durante o período letivo foram realizadas as seguintes atividades: Acompanhamento e orientação dos alunos regulares das disciplinas, quanto ao esclarecimento de dúvidas, através de revisões dos conteúdos teóricos ministrados em aula, auxiliando-os a uma melhor compreensão; Atividades de planejamento e elaboração supervisionada de aulas práticas, realizadas juntamente com o docente; Auxílio ao docente durante as aulas práticas realizadas no laboratório didático de botânica, através de coletas, com posterior herborização do material vegetal e preparação das amostras (montagem de exsicatas); Exames macroscópicos de representantes de diversos grupos de Angiospermas, tendo em vista estudo das estruturas morfológicas e práticas de identificação, através do uso de chaves de identificação para diagnose em nível de família. Todas estas atividades foram orientadas e supervisionadas junto aos professores de Morfologia e Anatomia Vegetal e Sistemática de Faneórgamas.

Coletas e observações de campo também foram realizadas no período de 2013.2 e 2014.1, nos jardins do CES/UFCG e também no Horto Florestal Olho d'água da bica, pertencente a essa Univesidade, para posterior cortes anatômicos, classificação dos tecidos epidérmico, vascular e parenquimático, bem como identificação de inclusões de substâncias orgânicas e inorgânicas. Os estudos se deram através de cortes histológicos e preparo destes para 
visualização em microscópio óptico, como também pela observação e reconhecimento de células, tecidos, estruturas e órgãos vegetais. Além da classificação morfológica da raiz, caule, folha, flor, fruto e semente das angiospermas. No final de cada semestre foram elaborados os relatórios finais, onde os mesmos foram apresentados a direção/ coordenação do curso de Licenciatura em Ciências Biológicas do CES/UFCG.

\section{Resultados}

As componentes curriculares Anatomia e Morfologia Vegetal, bem como Sistemática de Fanerógamas integram sub áreas da Botânica e compreendem, em sua grande maioria, conteúdos referentes aos caracteres morfológicos gerais das plantas, envolvendo estudos macro e microscópicos, com nomenclaturas e conceitos específicos, muitas vezes considerados aversivos, por serem trabalhados principalmente para a memorização (SILVA et al., 2014), o que nada contribui para uma aprendizagem com criticidade e percepção para a sua realidade (SANTOS E SODRÉ NETO, 2016). Estes conteúdos com linguagem bastante peculiar exigem intervenções práticas que possam articular a teoria a realidade através do contato direto com o objeto de estudo.

As atividades de monitoria, desenvolvidas na disciplina de Anatomia e Morfologia Vegetal serviram de subsídios para que os alunos compreendessem os conceitos relacionados a estruturas (Organografia) das plantas fanerógamas, que são importantíssimas para a classificação destas, no nível família dentro da Sistemática Vegetal. Compreender os significados dos conceitos é importante para 0 desenvolvimento e construção de novos conceitos (ARAÚJO; MOREIRA, 2005).

O exercicio da monitoria da disciplina Morfologia e Anatomia Vegetal foi procedidio com uma turma de 31 alunos, noturno. Essa componte currricular é obrigatória ofertada para a turma do $2^{\circ}$ período do curso de Licenciatura em Ciências Biológicas, com carga horária de 60 horas, equivalente a 4 créditos. 0 seguimento da disciplina foi realizado por aulas expositivas dialogadas, teóricas e práticas, na proporção de $30 \%$ e $70 \%$, respectivamente. As avaliações foram 
por meio de provas teóricas e práticas. Foi disponibilizado como material de estudos os livros clássicos de Anatomia Vegetal (CUTER, 1986; 1975; EZAU, 1974; FERRI, 1970; APEZATTO-DA-GLÓRIA, 2006). Dentre outros. A Carga horária prestada pelo monitor foi de 12 horas semais, perfazendo um total de 192 horas/semestrais.

No presente relato de experiência, registramos que trabalhar estes conceitos junto aos alunos de forma que os mesmos não ficassem presos apenas a uma série de palavras difíceis, sem relação com a sua realidade, foi desafiador, tendo em vista que os referidos alunos apresentaram carência de conhecimentos prévios relacionados aos temas abordados. Esta situação exigiu mais dedicação de estudos do monitor para dominar as explicações frente às dúvidas surgidas, uma vez que os alunos não conseguiam acompanhar e compreender todas as abordagens das aulas. Por se tratar de conteúdos extensos os alunos buscavam sanar todas as suas dúvidas na monitoria. Esta colocação já foi apontada por Baratto e Moreira (2015), que relata a procura da monitoria como salvação para os esclarecimentos e questionamento do que não ficou esclarecido na sala de aula.

Esta é uma realidade das Universidades, onde é comum os alunos chegarem aos cursos de Ensino Superior com uma bagagem ainda desordenada, apresentando dificuldade de relacionar os conhecimentos prévios com o universo de saberes mais aprofundados que as universidades exigem. Os alunos vêm do ensino básico com um método de aprendizagem ainda mecânico decorando conceitos, com pouco estímulo pra o raciocínio (ZLUHAN; RAITZ, 2014). O ensino superior se torna mais exigente regrado principalmente para o raciocínio crítico e argumentação contextualizada.

É compreensível que frente a essas novas exigências os alunos desencadeiem dificuldades e passem a precisar de auxílio para organizar todas as informações que vão chegando e associá-las às já existentes.

"O Ensino Superior depara-se, cada vez mais, com acadêmicos que apresentam dificuldades para atingir objetivos curricularmente prescritos, impostos pela necessidade de 0 aluno desenvolver competências e habilidades demandadas pelo mundo contemporâneo" (FRISON, 2016, p. 135). 
Percebeu-se, portanto, que a monitoria facilitou o prosseguimento dos estudos, pontuado por dúvidas não esclarecidas durante as aulas e trouxe aos alunos acolhimento as suas fragilidades de aprendizagem.

Para tentar esclarecer as dúvidas dos conceitos e as terminologias que regem a Anatomia Vegetal, a Morfologia, assim como a Sistemática de Fanerógamas, foram trabalhadas a teoria e a prática simultaneamente. Esta alternativa de ensino permitiu ao aluno o contato físico direto com o objeto de estudo juntamente com a teoria que o explica. $O$ material botânico foi 0 principal instrumento de estudo, e através deste material foi possível mostrar aos alunos os órgãos vegetativos e reprodutivos, como também os tecidos vegetais e suas classificações. Ao mesmo tempo em que os conceitos eram descritos para cada estrutura através das explicações seguindo e esquemas, a monitora sugeria aos alunos encontrar as estruturas in vivo (Figura 1).

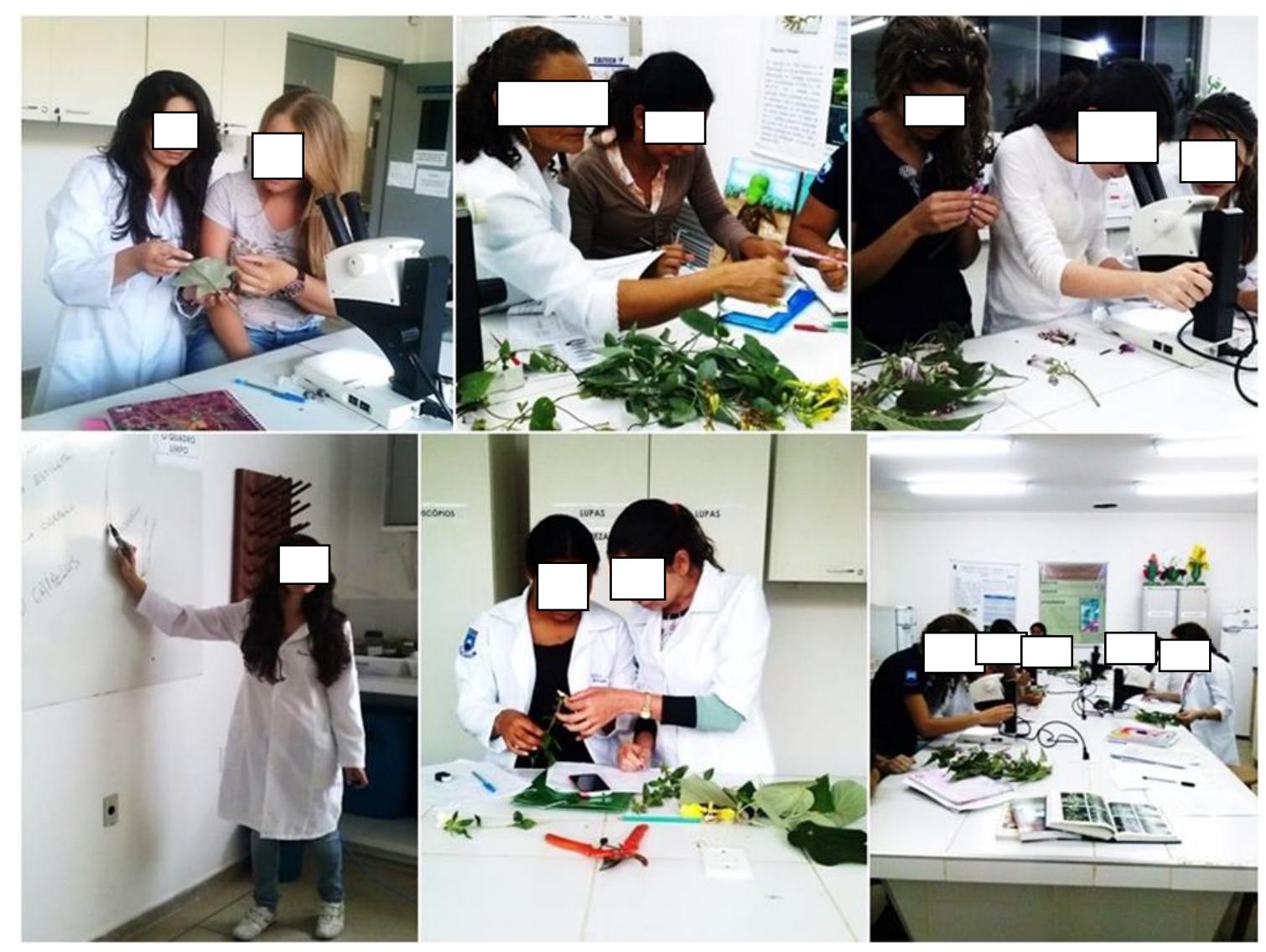

Figura 1: Registros do exercício da monitoria: atividades teorico-prática da disciplina Morfologia e Anatomia Vegetal, no Laboratório de Botânica do CES/ UFCG, periódo academico 2013.2

Fonte: Dados da Pesquisa, (2021) 
De acordo com Faria e Vilhalva (2016), que também se utilizou das metodologia teórico-prática para expor os conteúdos de botânica, os autores consideram esta alternativa como sendo:

\begin{abstract}
[...] indispensável a utilização de aulas-praticas no ensino de Botânica, especificamente anatomia vegetal, podendo preencher muitas lacunas deixadas pelo processo de transmissão-recepção de conhecimentos, favorecendo a construção pelos alunos de seus próprios conhecimentos num trabalho em grupo, a socialização de conhecimentos prévios e sua utilização para a construção de conhecimentos novos e mais elaborados (FARIA E VILHALVA, 2016, p. 220).
\end{abstract}

Esta maneira de trabalhar os conteúdos junto aos alunos mostra a iniciativa da monitora frente às dificuldades apresentadas pelos alunos, e a perspicácia da mesma em perceber que trabalhando a teoria e a prática conjuntamente seria uma alternativa que poderia mudar a maneira de exercitar a aprendizagem dos alunos e, consequentemente se obter um respaldo positivo na construção e consolidação dos conhecimentos. Isto evidencia que a monitora frente aos desafios encontrados já conseguiu se posicionar na tomada de decisões desenvolvendo suas habilidades para a prática de ensino. Esta percepção e posição mostra como o programa é importante para o aluno descobrir suas potencialidades no campo da docência. Corroborando, Lima e Ischiara (2016, p.1) apontam a monitoria como "um recurso de apoio pedagógico que pretende contribuir para o desenvolvimento de habilidades técnicas e intensificar o conhecimento teórico, facilitando a evolução acadêmica".

Trabalhar teoria e prática simultaneamente foi uma estratégia metodológica de ensino que auxiliou a monitora a retomar conteúdos já discutidos, em sala de aula com o professor e isto contribuiu para a monitora e os alunos ampliarem seus conhecimentos sobre o tema estudado. Sobre esta metodologia de ensino, Raniro e Raniro (2014, p. 180) dizem que "faz-se necessário desenvolver, nos professores em formação, competências profissionais com metodologias pautadas na articulação teoria-prática". Lira et al $(2016, s / p)$, argumenta que

\footnotetext{
"o monitor, ao unir teoria e prática, pode tornar-se autocrítico, um investigador da própria prática docente e responsável pelas demandas que possam surgir em sua área de atuação, observando suas limitações e habilidades, podendo assim aprimorá-las".
} 
Cortes histológicos do material botânico feitos à mão livre também foram realizados como atividades práticas. Este exercício foi proposto para que os alunos pudessem adquirir mais habilidades com a microtécnica vegetal, uma vez que esta prática com o professor é usualmente mais corrida, devido à carga horária e com um número elevado de alunos, dificultando a participação de todos. Na monitoria os alunos se mostraram mais à vontade, e isto trouxe mais segurança para que os mesmos pudessem realizar os cortes e manusear com mais calma o microscópio, bem como observar melhor as estruturas e assim compreender e distinguir cada tecido através das explicações da monitora e da visualização no microscópio.

No que se refere a monitoria na disciplina de Sistemática de Fanerógama, esta foi conduzida com turma noturna, constituída por 31alunos. A disciplina é ofertada no $3^{\circ}$ período do curso, com carga horária de $60 \mathrm{hrs,} \mathrm{correspondendo,}$ 4 créditos. A componente curricular foi administrada mediante aulas teóricas expositivas e dialogadas, seminários, aulas práticas de laboratório e atividade de campo (excursões para coleta de material botânico e observações de campo). As aulas prática ocorreram por meio da análise de espécimes, envolvendo a caracterização morfológica e identificação de angiospermas, seguida da preparação das plantas no laboratório (processo de herborização) para obtenção de exsicatas. As avaliações foram do tipo avaliação continuada com provas teóricas, teórico-práticas, relatórios das aulas práticas, trabalho prático, estudos dirigidos. As principais referencias bibliograficas indicadas como material de estudo foram (CRONQUIST, 1888; ANDREATTA; TRAVASSOS, 1989; RAVEN, EICHHORN APG II, 2003; RAVEN.; EVERT, 2008.; SOUZA, V. C.; LORENZI, 2008.; JUD et al., 2009; APG III, 2009).

A atuação da monitoria, foi acompanhar e auxiliar o professor orientador, na preparação das aulas teoricas, aulas de campo e, principalmente na preparação das aulas práticas de laboratório. A Carga horária prestada pelo monitor foi de 12 horas semanais, perfazendo um total de 192 horas/semestrais.

Quanto a percepção da monitora, em relação aos conhecimentos prévios dos alunos na disciplina Sistemática de Fanerógamas, foi perceptível o a existência de lacunas de aprendizagem por parte dos alunos, de modo, que 
uma parcela dos alunos apresentaram dificuldades extremas quanto à definição das estruturas morfológicas, e considera-se que estas lacunas sejam reflexo das deficiências de aprendizagem sobre os conceitos de Morfologia Vegetal, pois os conhecimentos dos caracteres morfológicos são necessários para o reconhecimento das estruturas das plantas e para classificação dos táxons no nível família botânica.

A participação como monitora nas disciplinas de Morfologia Vegetal e Sistemática de Fanerógamas foram extremamente importantes para acompanhar o processo de aprendizagem dos alunos, de modo a identificar as lacunas e a partir destas buscar subsídios para preenchê-las.

Detalhando melhor a percepção sobre tais lacunas de aprendizagem houve a compreensão de que os alunos não consolidaram os conceitos de Morfologia vegetal, uma vez que os mesmos não conseguiam aplicar os conhecimentos abordados na disciplina de Sistemática de Fanerógamas.

A dificuldade de uma parcela dos alunos em reconhecer os caracteres morfológicos dos vegetais para chegar a uma determinada família botânica utilizando a literatura especializada mostrou que os mesmos não conseguiram uma aprendizagem solida a respeito o significado dos conceitos básicos, pois no momento de aplicar esses conceitos não conseguiram associar as palavras às estruturas visualizadas no material de estudo. Por exemplo, na flor pentâmera os alunos não sabiam o significado estrutural e não conseguiam avançar na identificação do material botânico.

Várias atividades práticas utilizando material botânico foram realizadas para que os alunos tivessem contato com as estruturas e suas definições. Coletas de diversos exemplares de espécies fanerógamas foram realizadas para que os alunos pudessem manusear, observar as estruturas, utilizar as chaves de identificação e buscar classificá-las. Uma vez identificada a família de cada táxon, houve auxilio e explicações sobre os métodos de herborização para estes procedimentos práticos (Figura 2), e posteriormente a deposição das exsicatas na coleção do herbário da Universidade. Estas atividades instigaram os alunos a elucidar seus questionamentos, se colocarem como autônomos na busca e construção dos seus conhecimentos, sanando as 
deficiências e superando as dificuldades. Ao final da componente curricular foi possível observar um melhor desempenho dos alunos.

Esse melhor desempenho parte da percepção da monitora, sobre a mudança de posicionamento dos alunos que se mostraram mais, questionadores, com altivez, desenvoltura, participação e discussão durante as aulas práticas. Esse posicionamento dos alunos passou a ser mais frequentes durante os horários de atendimento da monitoria. O relato não conta com informações sobre o desempenho dos alunos nas avaliações, pois seria necessário uma analise documental de todas as avaliações realizadas com todos os alunos, que pudesse elucidar o desempenho de cada um.

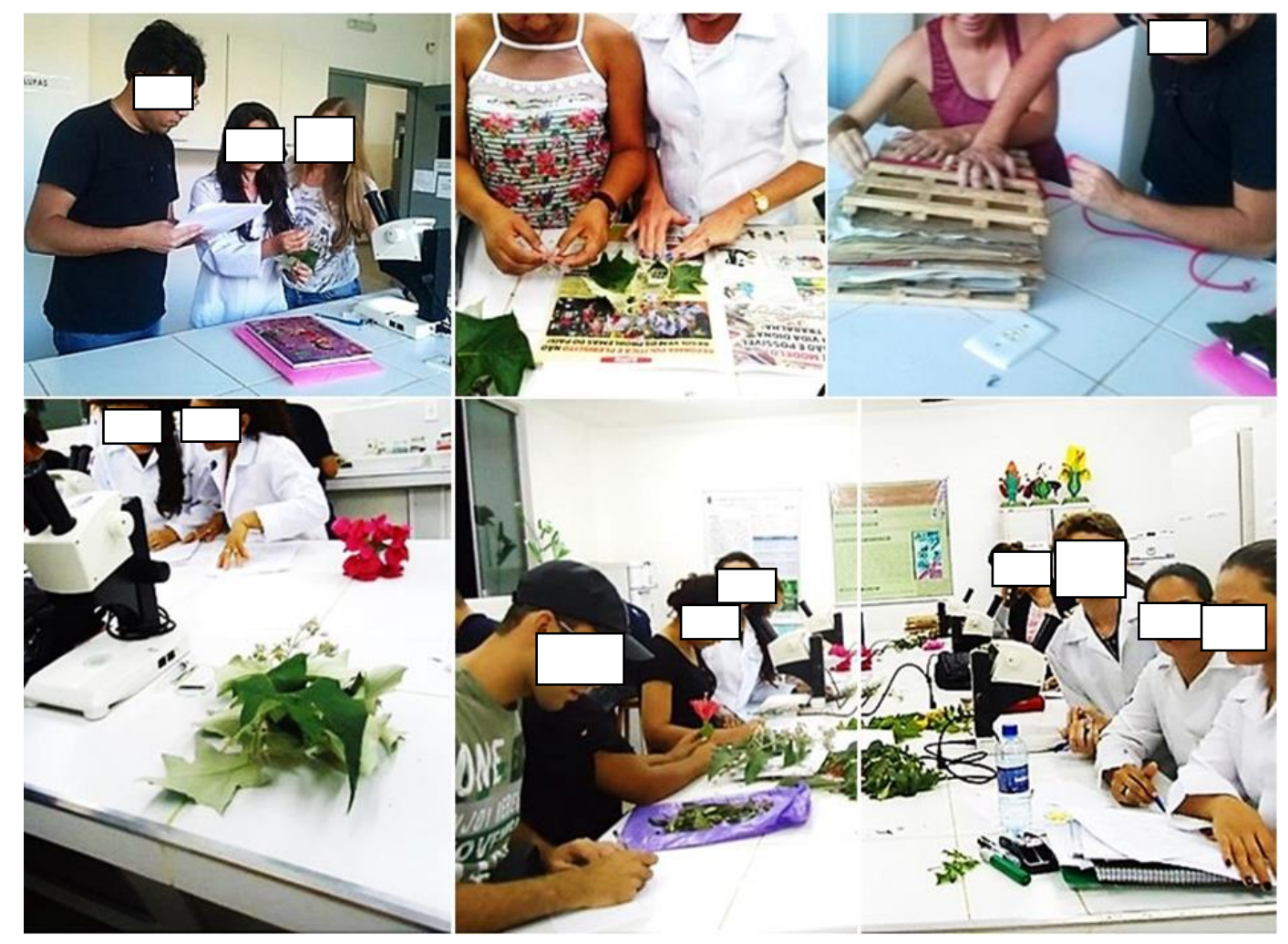

Figura 1: Registro das atividades práticas de monitoria: Identificação do material botãnico a nível de família utilizando chave analítica e preparação do material botânico para herborização na disciplina Sistemática de Fanerogmas, no laboratório de botânica do CES/UFCG, periódo 2014.1

Fonte: Dados da pesquisa, (2021) 


\subsection{Formação acadêmica do aluno monitor}

A participação na monitoria foi um diferencial na formação acadêmica, uma vez que a aproximou a uma área de estudo dentro do Curso de Ciências Biológicas. Essa aproximação se deu pelo tempo de estudo e pela busca para desenvolver as atividades teórico-práticas junto aos alunos, o que em muito contribuiu no aprimoramento do conhecimento no campo do ensino e da pesquisa na área de Botânica, A partir da monitoria foi possível a tomada de decisão sobre que linha de atuação seguir futuramente. De acordo com Ponte, Holanda e Andrade (2015, p. 6) a monitoria:

"É uma atividade que se propõe a inserir o acadêmico nas práticas de
ensino durante a graduação, ofertando-os a experiência da docência
como opção de carreira a ser levada adiante, preparando futuros
profissionais para o mercado de trabalho".

As atividades da monitoria foram extremamente importantes no sentido, de se enxergar como mediadora do conhecimento, partindo do momento em que a monitora deixa de se relacionar como colega de curso dos alunos e passa a exercer o papel de monitora, no qual foi se articulando as trocas de conhecimento, entre monitora e alunos, e esta troca contribuiu consideravelmente na consolidação do conhecimento nas disciplinas de Morfologia e Anatomia vegetal e de Sistemática de Fanerógamas de ambos os envolvidos. Esta consideração de como a monitoria é importante na construção do conhecimento também foi apontada por Fortes e Wilges (2015, p2), quando relataram que:

[...] o conhecimento, quando compartilhado, não se divide, multiplicase, gerando uma série de benefícios a todos os envolvidos nesse processo. Nesse sentido, a monitoria acadêmica é uma atividade significativamente formativa, pois proporciona uma troca de saberes que dificilmente aconteceriam se esse processo não se desse dentro da universidade.

Ir a campo, realizar coleta do material botânico, bem como preparar o material de laboratório e auxiliar tanto o professor quanto os alunos nas aulas práticas permitiu um maior contato com os materiais e melhor manuseio com 0 microscópio, lupa e montagem de lâminas, e este suporte configurou ao monitor atuar de forma confiante e desenvolver as atividades com mais 
segurança. Estas contribuições da monitoria também são compartilhadas por Matoso, quando relata que:

"O aprimoramento dos conhecimentos relacionados aos conteúdos
programáticos abordados e o desenvolvimento de atividades junto
aos docentes e acadêmicos do curso favoreceram-me maior
segurança e aprimoramento no desempenho como monitor"
(MATOSO, 2014, p. 80).

O empenho nas leitura e busca da compreensão dos conceitos que rege as disciplinas de Morfologia e Anatomia Vegetal e Sistemática de Fanerógamas, visando a construção de argumentos plausíveis, que pudessem esclarecer e solucionar as dúvidas dos alunos atendidos, foram sem dúvida uma das atividades mais relevante da monitoria, pois a dedicação e responsabilidade de ajudar no processo de ensino-aprendizagem proporcionou a monitora ampliação dos conhecimentos sobre os temas abordados e desenvoltura para conciliar a graduação e o exercício da monitoria. Esta dinâmica inseriu o na rotina da Universidade, na postura crítica e na tomada de decisões frente às situações vividas (SILVA; BELO, 2009).

Este resultado da monitoria corrobora a concepção de Lins et al. (2009) quando disserta que a monitoria compreende um laboratório de experiências vividas, onde novos horizontes e perspectivas acadêmicas são construídas através dos ensinamentos adquiridos junto ao professor e aos alunos monitorados.

As monitorias nas disciplinas de Morfologia e Anatomia Vegetal e de Sistemática de Fanerógamas aqui relatados, foram positivamente colaborativas para permanência e aprovação dos alunos nas disciplinas, bem como pela satisfação do professor orientador, uma vez que o mesmo concluiu no relatório da monitoria, reconhecendo que a monitoria ajudou significativamente para uma parcela de alunos que se tornaram mais participativos na relação professor-aluno-conhecimento. Na disciplina de Morfologia e Anatomia Vegetal de um total de trinta e um (31) alunos, vinte e nove (29) foram aprovados, um aluno (1) reprovado por falta e um (1) trancamento. Os resultados apontam que a maioria dos alunos conseguiram vencer as adversidades encontradas na disciplina e foram aprovados. Quanto aos resultados da disciplina Sistemática de Fanerógamas, a monitora não teve acesso a tais informações. 
A monitoria se insere nesta estatística com sua parcela de contribuição na aprovação de parte destes alunos, pois de acordo com o relatório final das atividades e a posição do professor supervisor, "à monitora correspondeu às expectativas para o desenvolvimento deste programa, alcançando os objetivos propostos, através do comprometimento com planejamento e execução das atividades. O desempenho final da turma foi satisfatório". (Recorte do relatório de avaliação do professor orientador sobre a monitora)

\subsection{Formação Docente}

Os cursos de Licenciatura estão direcionados a formar professores, muito embora somente os cursos não sejam o suficiente para ensinar o licenciando a ser professor em sua totalidade formativa. Na maioria das vezes, os critérios de avaliação dentro dos cursos de licenciatura estão embasados principalmente na reprodução dos conhecimentos abordados, mas raramente se avalia postura do futuro professor, quanto ao seu poder de argumentação, problematização e contextualização para ensinar.

"Aprender a ser professor, não é tarefa que se conclua após estudos de um aparato de conteúdos e técnicas de transmissão deles" (SILVA, 2010, p. 59). Frente a estas considerações, as licenciaturas não estão formando professores profissionais (GATTI, 2016). Ainda segundo Gatii, (2016) muitos cursos de Licenciatura se preocupam apenas em expor os conteúdos disciplinares que o professor vai abordar em sala de aula, e isto está muito distante da experiência da sala de aula.

Fazer parte do programa da monitoria proporcionou se inserir no universo docente, diferentemente do que ele estaria acostumado a viver somente em sala de aula. A monitoria o provocando-o (a) a tornar-se investigador do conhecimento e de metodologias de ensino que melhor se adequassem às suas limitações e às demandas de dificuldades de aprendizagem dos alunos atendidos.

Isto foi substancial na sua preparação, apropriação dos conhecimentos, qualificação, bem como do desenvolvimento de competências e habilidades, que mais tarde the servirão para atuar na docência de forma profissional (BABOSA; AZEVEDO; OLIVEIRA, 2014). Segundo Assis et al. (2006), a 
monitoria é apontada como uma iniciativa pertinente aos alunos que pretendem seguir à docência, pois seu exercício ajuda no desenvolvimento de suas habilidades e ampliação do conhecimento e aptidões para o campo de ensino. Esta percepção do autor corrobora as experiências vividas, pois a monitoria nesta perspectiva trouxe subsídio para descobrir se o mesmo apresenta ou não vocação para a docência e, com esta descoberta, prevenir futuramente 0 possível descontentamento com a carreira escolhida (MATOSO, 2014). Pois é no exercício da monitoria, bem como fazendo parte de outros programas de iniciação à docência, a exemplo PIBID, Estágio Supervisionado, Residência Pedagógica, dentre outros, se consegue vivenciar as sensações da docência que lhe servirão como ponto de partida na escolha de carreira.

Realizar as atividades da monitoria, principalmente através da explanação teórica para resolução de dúvidas, onde a monitora se colocou como mediador do conhecimento utilizando-se do quadro e de esquemas para explicar, explorar e buscar sanar as lacunas de aprendizagem dos alunos compreenderam as atividades que mais o aproximou da docência. Nestas atividades foi possível incorporar o papel do professor e atuou neste cenário como articulador do processo ensino aprendizagem.

Essa vivência de preparação e apropriação da carreira docente sentida durante a monitoria, corrobora a mesma percepção de outros monitores que também atuaram como monitores no Centro de Educação e Saúde da Universidade Federal de Campina Grande (CES/UFCG), como apontam Silva, Silva e Santos, (2018) de que são altamente relevantes os resultados da contribuição da monitoria na construção da personalidade docente, na capacitação de habilidades e competências e produção de conhecimento cientifico, configurando-se em um somatório de benefícios aos envolvidos.

Certamente essa concepção de alunos monitores perpassa o CES/UFCG, sendo também a realidade de alunos monitores de outras Instituições de Ensino Superior (IES) dentro das mais variadas áreas de Ensino. Baseando-se nestas deduções e inferências, nos faz refletir sobre a relevância da permanência e ampliação dos programas de monitorias dentro das instituições de ensino. 
Os benefícios do programa de monitoria, tanto para os alunos monitores, quanto para os alunos assistidos, pontuados neste relato, corrobora a percepção de outros monitores do programa de monitoria do CES/UFCG, como o trabalho de Silva, Silva e Santos (2018), que relata sobre as experiencias da monitoria na disciplina de Botânica. Neste relato os autores, enfatizam a relevância do programa tanto para os alunos monitores quando para a Instituição de Ensino, de modo que, para os alunos, especialmente de licenciatura se tem a oportunidade de conhecer mais proximamente os processos didáticos pedagógicos e iniciar os primeiros passos da profissão docente, bem como para Instituição, pelas contribuições que essa atividade traz para os demais acadêmicos.

Não obstante, o trabalho de Benegelania Pinto et al., (2016) traz a percepção dos alunos-monitores do curso de Enfermagem do CES/UFCG, sobre a contribuição da monitoria à formação do enfermeiro. Neste estudo, os autores concluíram que:

\begin{abstract}
A monitoria se constitui em uma ferramenta relevante no ensino universitário pela oportunidade de ampliação de experiências que contribuem para a formação acadêmica. Diante dessas possibilidades, este se torna essencial à formação do enfermeiro, devendo as instituições de ensino superior promovê-las e valorizá-las, de forma a somar às competências e habilidades do enfermeiro (BENEGELANIA PINTO et al., 2016, p. 1995).
\end{abstract}

Observa-se, portanto, que o programa de monitoria do CES/UFCG, tem contribuído significativamente para a formação profissional dos alunos, seja com a formação monitor (a), que vai desde a formação docente, ou em outros aspectos, como a formação do enfermeiro, seja com a formação acadêmica dos alunos assistido. Neste sentido, os benefícios são mútuos, professores, monitores, alunos e, a Instituição são positivamente favorecidos com programa de Monitoria.

\title{
Conclusão
}

De maneira geral o programa de monitoria foi para a monitora um diferencial no seu crescimento e desenvolvimento dentro da academia, bem como estimuladora para atuação docente, pois as atividades realizadas e as experiências vividas juntos aos alunos e o professor (a) orientador trouxeram subsídios que contribuíram no aperfeiçoamento da formação acadêmica e 
formação inicial docente. Através do exercício da monitoria foi possivel a identificação por uma linha de pesquisa que o influenciou na escolha de carreira.

Além da contribuição do progrma de monitoria na formação acadêmica e docente da monitora, o programa também permitiu a mesma, desenvolver a capacidade de trabalho em grupo, a socialização da monitora com os alunos, promoveu um acolhimento aos mesmos, deixando-os mais confortáveis em externar suas dúvidas, tornando-os mais desenvoltos e com conhecimentos botânicos mais consolidados. Sem dúvida, esse foi o resultado mais satisfatório para a monitora, um feedback que a fez perceber o alcance de atingir os objetivos propostos pelo programa.

Conclui-se portanto que o programa contribuiu consideravelmente na apropriação dos conhecimentos que envolve os conteúdos de Morfologia, Anatomia Vegetal e Sistemática de Fanerógamas, transformando a postura do aluno passivo para a do aluno investigador, onde passou a desenvolver pesquisas e trabalhos na área de Botânica, que the direcionou para a escolha do trabalho de conclusão de curso, como também em produções de trabalhos que renderam publicações em eventos científicos. Em suma estes resultados apontam a relevância da monitoria no crescimento profissional do monitor licenciando e no desenvolvimento do programa e da universidade.

\section{Referências}

AMATO, D. T.; REIS A. C. A percepção dos monitores sobre o programa de monitoria do Ensino Superior do CEFET/RJ. Scientia Plena, v. 12, n. 07, 2016.

ANDREATTA, R. H. P.; TRAVASSOS, O. P. Chaves para determinar as famílias de Pteridophyta, Gymnospermae e Angiospermae. Edit. Univ. Santa Úrsula, 1989.

APEEZZATO-DA-GLORIA, B.; CARMELO-GUERREIRO, S.M. Anatomia Vegetal. 2 ed. Ed. UFV, Viçosa, 2006.

APG II. An update of the Angiosperm Phylogeny Group classification for the orders and families of flowering plants: APG II. Botanical Journal of the Linnaean Society, London, v. 141, p. 399-436, 2003.

APG III. An update of the Angiosperm Phylogeny Group classification for the orders and families of flowering plants: APG III. Botanical Journal of the Linnean Society, London, v. 161, p. 105-121, 2009. 
ARAÚJO, R; MOREIRA, L.F.N. Monitoria da disciplina de Cálculo. In: Anais Congresso Brasileiro de ensino de engenharia. Vol. 33, 2005.

ASSIS, F.; BORSATTO, A. Z.; SILVA, P. D.D.; PERES, P. L.; ROCHA, P.R.; LOPES, G. T. Programa de monitoria acadêmica: percepções de monitores e orientadores. Rev. Enferm. UERJ, v. 14, n. 3, p. 391-397, 2006.

BARATTO, P.F.B.; MOREIRA, V. S. Expectativa de aprovação com a monitoria para os componentes curriculares de física no ensino superior. In: Anais do Salão Internacional de Ensino, Pesquisa e Extensão, v. 7, n. 1, 2015.

BARBOSA, M.B.; AZEVEDO, M. E. O.; OLIVEIRA, M.C.A. Contribuições da monitoria acadêmica para o processo de formação inicial docente de Licenciandos do Curso de Ciências Biológicas da FACEDI/UECE. SBEnBio, n. 7, 2014.

BENEGELANIA PINTO, M., ARAÚJO MEDEIROS, C. S., FARIAS DE ANDRADE, L. D.; CARVALHO DE BRITO SANTOS, N. C.; Montenegro De Albuquerque, A., ANDRADE RAMALHO, M. N. Monitoria acadêmica: importância e contribuição para a formação do Enfermeiro. Journal of Nursing UFPE/Revista de Enfermagem UFPE, v. 10, n.6, p. .2016.

BRASIL, Leis. Lei o 5.540, de 28 de novembro de 1968. Fixa normas de organização e funcionamento do ensino superior e sua articulação com a escola média, e dá outras providências. Diário Oficial da União, p. 10369, 1968.

CRONQUIST, A. The evolution and classification of the flowers plants. The New York Botanical Garden, New York, 1988.

FARIA, M. T.; VILHALVA, D. A. A. Importância das aulas práticas na disciplina de Anatomia Vegetal, curso de extensão: descrição da anatomia foliar e histoquímica de Plectranthus barbatus Andrews (LAMIACEAE). RENEFARA, v. 10, n. 10, p. 214-223, 2016.

FERNANDES, J.; ABREU, T.A.; DANTAS, A.J.L.; SILVA, A.M.S. Influência da Monitoria Acadêmica no Processo de Ensino e Aprendizagem. Clínica \& Cultura, v. 5, n. 2, 2016.

FORTES, C.H.M.; WILGES, C.H.M. A importância da monitoria no ensinoaprendizagem na disciplina de anatomia animal I. In: Anais, XX Congresso Interinstitucional de Ensino Pesquisa e Extensão UNICRUZ, 2015.

FRISON, L. M. B. Monitoria: uma modalidade de ensino que potencializa a aprendizagem colaborativa e autorregulada. Pro-Posições, v. 27, n. 1, p. 133153, 2016.

FRISON, L. M. B.; MORAES, M. A. C. de. As práticas de monitoria como possibilitadoras dos processos de autorregulação das aprendizagens discentes. Poíesis Pedagógica, v. 8, n. 2, p. 144-158, 2010.

GATTI, B. A. Formação de professores: condições e problemas atuais. Revista Internacional de Formação de Professores, v. 1, n. 2, 2016. 
GIL, A. C. Pesquisa social. In. Métodos e técnicas de pesquisa social. 6. ed. São Paulo: Atlas, 2008.

JUDD, W. S.; CAMPBELL, C. S.; KELLOGG, E.; STEVENS, P.; DONOGHUE, M. Sistemática Vegetal: Um enfoque filogenético. 3. ed. (trad.). Porto Alegre: Artmed, 2009.

LIMA, C. P. L.; ISCHIARA, J.C. A RELEVÂNCIA DA MONITORIA PARA A FORMAÇÃO ACADÊMICA DO MONITOR EM PSICOLOGIA. Encontro de Extensão, Docência e Iniciação Científica (EEDIC), v. 3, n. 1, 2016.

LIRA, M.O.; NASCIMENTO, D.Q.; SILVA, G.C.; MARMAN, A.S. Contribuições da monitoria acadêmica para o processo de formação inicial docente de licenciandos em Ciências Biológicas da UEPB. In: Anais- II Conedu-Congresso Nacional de Educação.

p.9, 2016.

MATOSO, L. M.L. A importância da monitoria na Formação acadêmica do monitor: Um relato de experiência. Catussaba, v. 3, n. 2, p. 77-83, 2014.

MUNIZ, C. E.S.; ALMEIDA, A. Z. F.; CARDOSO, M. K. B.; PAIVA, C. A.; LIMA, V E.; LARANJEIRA, E. Questionando a monitoria: intenções e práticas no ensino superior. In: Anais, I Congresso Internacional de Educação e Inclusão. v.1, 2014.

PONTE, K.P.; HOLANDA, M.T.S.; ANDRADE, A.G.S. Contribuições do programa de monitoria para a formação acadêmica e iniciação à docência: uma reflexão a partir do referencial histórico-cultural. Cadernos de Graduação, v. 2, n. 3, p. 1-17, 2015.

RANIRO, C.; RANIRO, J. Trabalhando com teoria e prática: artes visuais e artes cênicas na formação continuada de professores. Revista Educação e Linguagens, v. 4, n. 6, 2015.

RAVEN, P. H.; EVERT, R. F. \& EICHHORN, S.E. Biologia vegetal. $7^{a}$ ed. Rio de Janeiro: Guanabara Koogan. 2007.

SANTOS, E.A.V.; SODRÉ NETO. Dificuldades no ensino-aprendizagem de Botânica e possíveis alternativas pelas abordagens de Educação Ambiental e Sustentabilidade. Educação Ambiental em Ação. n.58, 2016.

SANTOS, M. M. D.; LINS, N. D. M. A monitoria como espaço de iniciação à docência: possibilidades e trajetórias. Natal: EDUFRN, 2007.

SILVA, A. V. A articulação entre teoria e prática na construção do conhecimento pedagógico do conteúdo. Revista espaço acadêmico, v. 10, n. 112, p. 58-66, 2010.

SILVA, M.O.; SILVA, C.F.; SANTOS, E. A.V. As possibilidades da monitoria para a formação docente: um relato de experiência no curso de Ciências Biológicas. Educação, Ciência e Saúde, v. 5, n. 2, 2018.

SILVA, R. N.; BELO, M. L. M. Experiências e reflexões de monitoria: contribuição ao ensino-aprendizagem. Scientia Plena, v. 9, n.7, 2012. 
SILVEIRA, E.; SALES, F. A importância do Programa de Monitoria no ensino de Biblioteconomia da Universidade do Estado de Santa Catarina (UDESC). InCID: Revista de Ciência da Informação e Documentação, v. 7, n. 1, p. 131-149, 2016.

SOUZA, R.O.; GOMES, A.R A eficácia da monitoria no processo de aprendizagem visando a permanência do aluno na IES. Revista

Interdisciplinar do Pensamento Científico. v.1, n.2, p.230-238, 2015.

SOUZA, V. C.; LORENZI, H. Botânica Sistemática: Guia ilustrado para identificação das famílias de Fanerógamas nativas e exóticas no Brasil, baseado em APG II. 2. Ed. Nova Odessa: Instituto Plantarum, 2008. 704p.

VICENZI, C. B.; CONTO, F.; FLORES, M.E.; ROVANI. G.; FERRAZ, S.C.C.; MAROSTEGA, M.G. A monitoria e seu papel no desenvolvimento da formação acadêmica. Revista Ciência em Extensão. v.12, n.3, p.88-94, 2016.

ZLUHAN, M. R.; RAITZ, T. R. Um estudo com jovens: transição do Ensino Médio ao Ensino Superior. X ANPED SUL, p. 21, 2014. 